\title{
Mechanistic modeling of the SARS-CoV-2 disease map
}

\author{
Kinza Rian ${ }^{1 \dagger}$, Marina Esteban-Medina ${ }^{1,2+}$, Marta R. Hidalgo ${ }^{3}$, Cankut Çubuk ${ }^{1}$, Matias M. Falco ${ }^{1,4}$, Carlos Loucera ${ }^{1,2}$, \\ Devrim Gunyel $1^{5}$, Marek Ostaszewski ${ }^{5}$, María Peña-Chilet ${ }^{1,2,4^{*}}$ and Joaquín Dopazo ${ }^{1,2,4,6^{*}}$ (D)
}

\author{
* Correspondence: maria.pena.chilet. \\ ext@juntadeandalucia.es; joaquin. \\ dopazo@juntadeandalucia.es \\ ${ }^{\dagger}$ Kinza Rian and Marina Esteban- \\ Medina contributed equally to this \\ work. \\ ${ }^{1}$ Bioinformatics Area, Fundación \\ Progreso y Salud (FPS), Hospital \\ Virgen del Rocío, Sevilla, Spain \\ Full list of author information is \\ available at the end of the article
}

\begin{abstract}
Here we present a web interface that implements a comprehensive mechanistic model of the SARS-CoV-2 disease map. In this framework, the detailed activity of the human signaling circuits related to the viral infection, covering from the entry and replication mechanisms to the downstream consequences as inflammation and antigenic response, can be inferred from gene expression experiments. Moreover, the effect of potential interventions, such as knock-downs, or drug effects (currently the system models the effect of more than 8000 DrugBank drugs) can be studied. This freely available tool not only provides an unprecedentedly detailed view of the mechanisms of viral invasion and the consequences in the cell but has also the potential of becoming an invaluable asset in the search for efficient antiviral treatments.
\end{abstract}

Keywords: Mechanistic modeling, Signaling pathway, Drug discovery, COVID-19, Systems biology

\section{Introduction}

The recent pandemic of COVID-19 (Coronavirus Disease-2019), an emerging respiratory disease caused by the SARS-CoV-2 virus, which spread more efficiently than previous highly pathogenic coronaviruses SARS-CoV and MERS-CoV, has led to a tremendous toll of affected cases and over 500,000 fatalities in more than 200 countries since its first outbreak in late 2019 [1]. Precisely due to the rapid transmission of this novel pathogen, no antiviral drugs or vaccines are available for SARS-CoV-2.

Understanding the molecular mechanisms that mediate SARS-CoV-2 infection is key for the rapid development of efficient preventive or therapeutic interventions against the COVID-19. A comprehensive description of such molecular mechanisms is represented in the corresponding disease map, that is, the sub-module of the whole pathway of known human protein functional interactions that summarize details of the disease mechanism and consequently are relevant for understanding the disease [2]. The recent availability of a detailed catalog of viral-human protein interactions [3] has

(c) The Author(s). 2021 Open Access This article is licensed under a Creative Commons Attribution 4.0 International License which permits use, sharing, adaptation, distribution and reproduction in any medium or format, as long as you give appropriate credit to the original author(s) and the source, provide a link to the Creative Commons licence, and indicate if changes were made. The images or other third party material in this article are included in the article's Creative Commons licence, unless indicated otherwise in a credit line to the material. If material is not included in the article's Creative Commons licence and your intended use is not permitted by statutory regulation or exceeds the permitted use, you will need to obtain permission directly from the copyright holder. To view a copy of this licence, visit http://creativecommons.org/licenses/by/4.0/. The Creative Commons Public Domain Dedication waiver (http://creativecommons.org/publicdomain/zero/1.0/) applies to the data made available in this article, unless otherwise stated in a credit line to the data. 
facilitated the construction of a first version of a map of the human molecular pathways involved in the viral infection and downstream consequences [4].

Disease maps are repositories of knowledge of disease-relevant mechanisms that provide qualitative guidance for the interpretation of experimental findings [2]. Actually, disease maps are the supporting foundation of different tools able to model the information contained in them in order to provide a detailed quantitative explanation for experimental results [5]. In particular, mechanistic models of disease maps are becoming increasingly relevant for genomic data interpretation because they provide a natural link between omics data measurements and cell behavior and outcome [6], which ultimately accounts for the phenotype of the infection. The knowledge of these links allows a better understanding of the molecular mechanisms of the viral infection and the responses to drugs. Actually, mechanistic models of human signaling [7] or metabolic pathways [8] have been successfully used to uncover specific molecular mechanisms behind different cancers [7, 9-11], rare [12] and common [13] diseases, to reveal mechanisms of action of drugs [14], and dissecting them at single cell level [15], to suggest personalized treatments $[16,17]$ and in other biologically interesting scenarios $[18,19]$. Basically, mechanistic models analyze experimental values in the context of the disease map information, which is used to point out the relevant aspects of the molecular mechanisms behind the experiment. It is important to note that this assessment is made from a systems biology perspective, in the holistic context of the disease map, and considers the functional interactions among the gene products as described in the map. Typically, these experimental values are gene expression transcriptomic data, although other data such as proteomic, phosphoproteomic, genomic [20], or even methylomics, can also be used. Interestingly, beyond its usefulness for the functional interpretation of experimental results, the most remarkable property of mechanistic models is that they can be used to predict the effects of interventions (inhibitions, overactivations, drugs, etc., alone or in combinations) over proteins of the map in the condition studied [21]. Therefore, this opens the possibility of using these models for exploring new therapeutic options as well [22].

\section{Methods}

To construct a first approach to the COVID-19 disease map, the SARS-CoV-2 virushuman interactome was firstly expanded from existing KEGG pathways [23] to define regions within the whole set KEGG pathways that potentially account for the molecular mechanism of the viral infection and the downstream consequences. Pathways are composed of individual signaling circuits (sub-pathway that describes the chain of signal transduction that connects a receptor protein to an effector protein) whose functionalities can be described by the UniProt [24] functional annotations of their effector nodes $[7,25]$. It order to restrict the map to those circuits relevant for the COVID-19 disease mechanism, only signaling circuits with at least one UniProt [24] function that fit in one of these virus-related categories: 1) Host-virus interaction, 2) inflammatory response, 3) immune activity, 4) antiviral defense, 5) endocytosis were selected to define the COVID-19 disease map. The model presented here is a part of an ongoing more detailed repository of SARS-CoV-2 mechanisms, the COVID-19 Disease Map, in construction by an international community, whose most recent version is available at: https://doi.org/10.17881/covid19-disease-map. In addition to the human version of the 
COVID-19 map, versions for animal models, like mouse or rat, using the homologous pathways are also provided by the tool [4].

The mechanistic model implemented here takes a directed graph (in this case a first version of the COVID-19 map, and in the future new versions as these are released), and extracts from it the collection of signaling circuits that connect receptor nodes to effector nodes. The signal transduction across such circuits, $S_{n}$, is estimated using gene expression values as proxies of protein activity [26] using the following recursive equation [7]:

$$
S_{n}=v_{n} \cdot\left(1-\prod_{s_{a} \in A}\left(1-s_{a}\right)\right) \cdot \prod_{s_{i} \in I}\left(1-s_{i}\right)
$$

$S_{n}$ is the signal intensity for the current node $n, v_{n}$ is its normalized gene expression value, $A$ is the set of activation signals $\left(s_{a}\right)$, arriving to the current node from activation edges, Iis the set of inhibitory signals $\left(s_{i}\right)$ arriving to the node from inhibition edges. The $S_{n}$ values of circuits are further used in comparisons to detect increases or decreases in signaling activity (and consequently in the corresponding cell functionality), or to infer the effect of interventions in signaling or the potential resulting phenotype of mutations.

\section{Implementation}

Here, we present the first implementation of a mechanistic model of the SARS-CoV-2 infection in a user-friendly web interface. The model used here implements the HiPathia [7] algorithm, which has demonstrated to outperform other competing algorithms in a recent benchmarking [25]. The mechanistic model implemented in HiPathia has been successfully used to understand the disease mechanisms behind different cancers [7] and was able to predict cancer vulnerabilities with a high precision [9]. The model has been implemented in a user-friendly web application that inputs normalized gene expression values (or similar proteomics or phosphoproteomic values) and can be found at http://hipathia.babelomics.org/covid19/. As an example, we carried out some analyses that involve a case-control differential signaling analysis using a recently published gene expression experiment [27] with human lung cell lines infected with SARS-CoV-2 (GEO id: GSE147507, the dataset GSE147507_RawReadCounts_ Human.ts). The infected cells showed a differential activation pattern in circuits related to virus entrance to cell, activation of immune, inflammatory and other virus-triggered responses (see Fig. 1a and Table 1 for a detailed list of differentially activated signaling circuits and Table 2 for detail on the differentially activated cell functionalities). Interestingly, several of the deregulated pathways include TNF, a target gene of chloroquine, one of the drugs with promising results against COVID-19 [28]. Moreover, NF-kB signaling pathway has been highlighted in several studies as one of the main pathways responsible for COVID-19 progression [29] (Fig. 1 B). Figure 1c depicts the heathmap of signaling activity profiles that discriminate the two classes of samples (cases and controls) compared. The results found are consistent with those of previous analyses with the same data, where a modest but generalized response of mechanisms related to immune response and inflammatory processes, such as response to chemokine and 


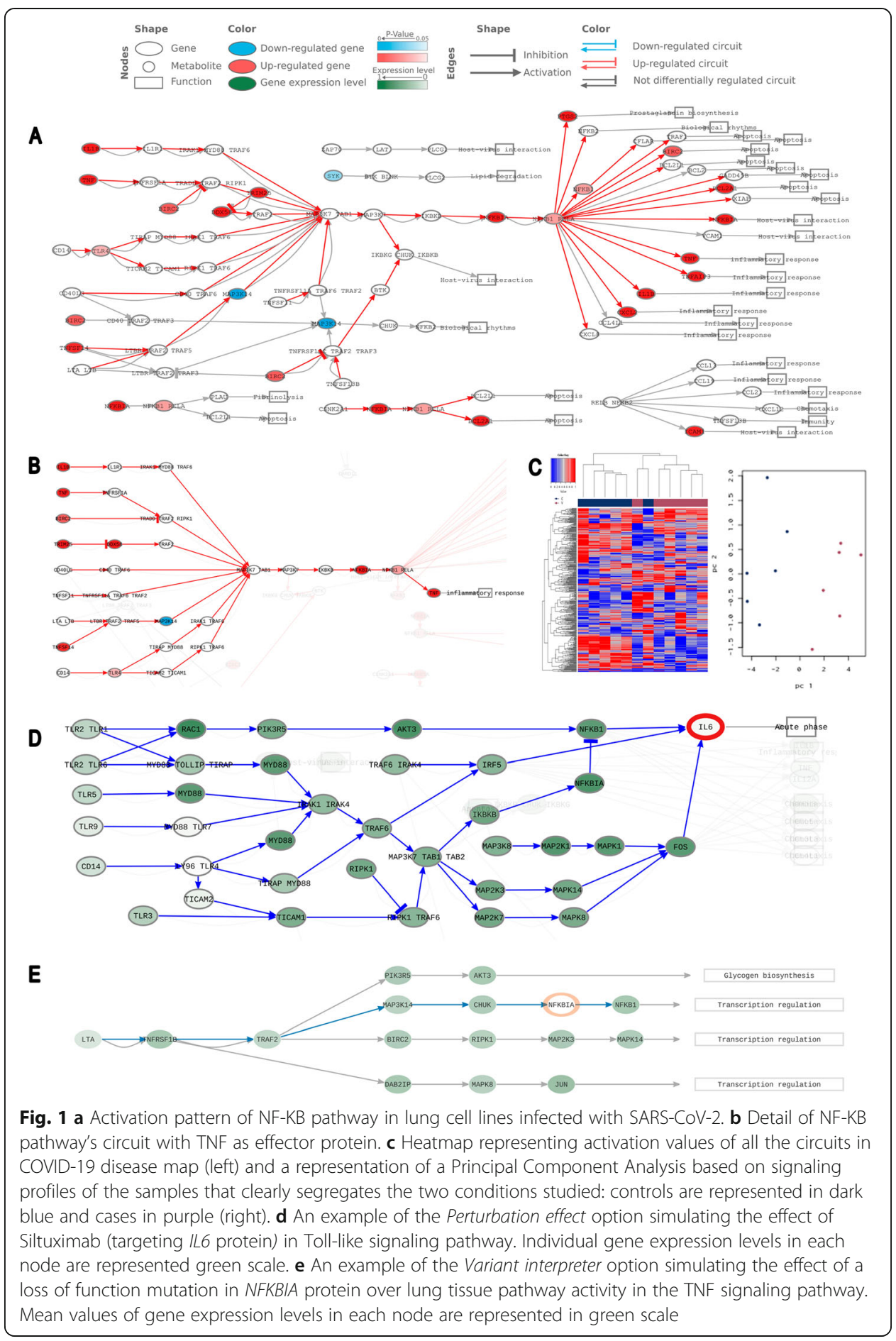

cytokines, virus defense-related processes, and other general functions of cell like apoptosis or cell differentiation was demonstrated [27]. Interestingly, the processes highlighted by the authors are response to chemokines and interferon-related signaling pathways. Both processes are highly associated with pathways in whose circuits our model detect significant deregulations (see Table 1), such as Toll-like and TNF signaling pathways. The relation between chemokines, interferon and Toll-like signaling is 
Table 1 Circuits from CoV-Hipathia differentially activated in lung cell lines infected with SARS-CoV-2

KEGG pathway: effector gene/s

MAPK signaling pathway: NLK

MAPK signaling pathway: STK3

MAPK signaling pathway: ECSIT, TRAF6

Ras signaling pathway: REL

Ras signaling pathway: MLLT4

NF-kappa B signaling pathway: CFLAR

NF-kappa B signaling pathway: BIRC2

NF-kappa B signaling pathway: XIAP

NF-kappa B signaling pathway: BCL2L1

NF-kappa B signaling pathway: GADD45B

NF-kappa B signaling pathway: BCL2A1

NF-kappa B signaling pathway: NFKB2

NF-kappa B signaling pathway: CXCL8

NF-kappa B signaling pathway: IL1B

NF-kappa B signaling pathway: TNFAIP3

NF-kappa B signaling pathway: NFKBIA

NF-kappa B signaling pathway: PTGS2

NF-kappa B signaling pathway: CXCL2

NF-kappa B signaling pathway: IKBKG, CHUK, IKBKB

NF-kappa B signaling pathway: BCL2L1

NF-kappa B signaling pathway: BCL2A1

HIF-1 signaling pathway: TIMP1

HIF-1 signaling pathway: TIMP1

HIF-1 signaling pathway: EDN1

HIF-1 signaling pathway: NOS2

HIF-1 signaling pathway: PDK1

HIF-1 signaling pathway: PGK1

HIF-1 signaling pathway: LDHA

mTOR signaling pathway: VEGFA

mTOR signaling pathway: TSC1

PI3K-Akt signaling pathway: BCL2L11

Apoptosis: FADD, TRADD

Apoptosis: IRAK3, MYD88

Toll-like receptor signaling pathway: CXCL10

Toll-like receptor signaling pathway: IFNA1

Toll-like receptor signaling pathway: IL1B

Toll-like receptor signaling pathway: IL6

RIG-I-like receptor signaling pathway: MAPK14

RIG-I-like receptor signaling pathway: MAVS, TMEM173 UP

RIG-I-like receptor signaling pathway: IRF7

Ras signaling pathway: MAPK8

NF-kappa B signaling pathway: TRAF1

NF-kappa B signaling pathway: TNF

HIF-1 signaling pathway: TFRC

UP

UP/ DOWN statistic $p$-value ${ }^{a} \quad$ FDR $^{\mathrm{b}} \quad \mathrm{FC}^{\mathrm{c}} \quad \log \mathrm{FC}$

UP

UP

UP

UP

UP

UP

UP

UP

UP

UP

UP

UP

UP

UP

UP

UP

UP

UP

UP

UP

UP

UP

UP

UP

UP

UP

UP

UP

DOWN

DOWN

UP

UP

UP

UP

UP

UP

UP

P

UP

UP

UP

UP

2.882

$\begin{array}{llll}2.16 \mathrm{E}-03 & 0.023 & 1.098 & 0.135\end{array}$

2.882

2.882

2.882

2.882

2.882

2.882

2.882

2.882

2.882

2.882

2.882

2.882

2.882

2.882

2.882

2.882

2.882

2.882

2.882

2.882

2.882

2.882

2.882

2.882

2.882

2.882

2.882

2.882

$-2.882$

$-2.882$

2.882

2.882

2.882

2.882

2.882

2.882

2.882

2.882

2.882

2.722

2.722

2.722

2.722

$\begin{array}{llll}2.16 \mathrm{E}-03 & 0.023 & 1.209 & 0.274\end{array}$

$\begin{array}{lllll}2.16 \mathrm{E}-03 & 0.023 & 1.182 & 0.241\end{array}$

$\begin{array}{lllll}2.16 \mathrm{E}-03 & 0.023 & 1.074 & 0.103\end{array}$

$\begin{array}{lllll}2.16 \mathrm{E}-03 & 0.023 & 1.049 & 0.069\end{array}$

$\begin{array}{llll}2.16 \mathrm{E}-03 & 0.023 & 1.212 & 0.278\end{array}$

$\begin{array}{lllll}2.16 \mathrm{E}-03 & 0.023 & 1.261 & 0.335\end{array}$

$\begin{array}{lllll}2.16 \mathrm{E}-03 & 0.023 & 1.176 & 0.234\end{array}$

$\begin{array}{lllll}2.16 \mathrm{E}-03 & 0.023 & 1.193 & 0.254\end{array}$

$\begin{array}{lllll}2.16 \mathrm{E}-03 & 0.023 & 1.179 & 0.238\end{array}$

$\begin{array}{lllll}2.16 \mathrm{E}-03 & 0.023 & 1.570 & 0.651\end{array}$

$\begin{array}{llll}2.16 \mathrm{E}-03 & 0.023 & 1.225 & 0.293\end{array}$

$\begin{array}{llll}2.16 \mathrm{E}-03 & 0.023 & 1.185 & 0.245\end{array}$

$\begin{array}{llll}2.16 \mathrm{E}-03 & 0.023 & 1.341 & 0.424\end{array}$

$\begin{array}{lllll}2.16 \mathrm{E}-03 & 0.023 & 1.311 & 0.390\end{array}$

$\begin{array}{llll}2.16 \mathrm{E}-03 & 0.023 & 1.254 & 0.327\end{array}$

$\begin{array}{llll}2.16 \mathrm{E}-03 & 0.023 & 1.267 & 0.341\end{array}$

$\begin{array}{llll}2.16 E-03 & 0.023 & 1.335 & 0.417\end{array}$

$\begin{array}{llll}2.16 E-03 & 0.023 & 1.110 & 0.151\end{array}$

$\begin{array}{llll}2.16 E-03 & 0.023 & 1.098 & 0.135\end{array}$

$\begin{array}{llll}2.16 \mathrm{E}-03 & 0.023 & 1.448 & 0.534\end{array}$

$\begin{array}{llll}2.16 \mathrm{E}-03 & 0.023 & 1.051 & 0.072\end{array}$

$\begin{array}{llll}2.16 \mathrm{E}-03 & 0.023 & 1.051 & 0.072\end{array}$

$\begin{array}{llll}2.16 \mathrm{E}-03 & 0.023 & 1.121 & 0.164\end{array}$

$\begin{array}{llll}2.16 \mathrm{E}-03 & 0.023 & 1.585 & 0.664\end{array}$

$\begin{array}{lllll}2.16 \mathrm{E}-03 & 0.023 & 1.037 & 0.052\end{array}$

$\begin{array}{llll}2.16 \mathrm{E}-03 & 0.023 & 1.048 & 0.068\end{array}$

$\begin{array}{llll}2.16 \mathrm{E}-03 & 0.023 & 1.047 & 0.066\end{array}$

$\begin{array}{llll}2.16 \mathrm{E}-03 & 0.023 & 1.059 & 0.083\end{array}$

$\begin{array}{lllll}2.16 \mathrm{E}-03 & 0.023 & 0.946 & -0.080\end{array}$

$\begin{array}{lllll}2.16 \mathrm{E}-03 & 0.023 & 0.918 & -0.123\end{array}$

$\begin{array}{llll}2.16 \mathrm{E}-03 & 0.023 & 1.118 & 0.161\end{array}$

$\begin{array}{llll}2.16 \mathrm{E}-03 & 0.023 & 1.167 & 0.223\end{array}$

$\begin{array}{llll}2.16 \mathrm{E}-03 & 0.023 & 1.518 & 0.602\end{array}$

$\begin{array}{lllll}2.16 \mathrm{E}-03 & 0.023 & 1.486 & 0.572\end{array}$

$\begin{array}{lllll}2.16 \mathrm{E}-03 & 0.023 & 1.172 & 0.229\end{array}$

$\begin{array}{llll}2.16 \mathrm{E}-03 & 0.023 & 1.526 & 0.610\end{array}$

$\begin{array}{lllll}2.16 \mathrm{E}-03 & 0.023 & 1.214 & 0.280\end{array}$

$\begin{array}{lllll}2.16 \mathrm{E}-03 & 0.023 & 1.204 & 0.268\end{array}$

$\begin{array}{llll}2.16 \mathrm{E}-03 & 0.023 & 1.540 & 0.623\end{array}$

$\begin{array}{llll}4.33 \mathrm{E}-03 & 0.035 & 1.043 & 0.061\end{array}$

$\begin{array}{lllll}4.33 \mathrm{E}-03 & 0.035 & 1.193 & 0.254\end{array}$

$\begin{array}{lllll}4.33 \mathrm{E}-03 & 0.035 & 1.639 & 0.713\end{array}$

$\begin{array}{lllll}4.33 \mathrm{E}-03 & 0.035 & 1.049 & 0.068\end{array}$ 
Table 1 Circuits from CoV-Hipathia differentially activated in lung cell lines infected with SARS-CoV-2 (Continued)

\begin{tabular}{lllllll}
\hline KEGG pathway: effector gene/s & UP/ DOWN & statistic & $\boldsymbol{p}$-value & FDR $^{\mathbf{b}}$ & FC $^{\mathbf{c}}$ & log FC $^{\text {F }}$ \\
\hline Sphingolipid signaling pathway: SMPD2 & UP & 2.722 & $4.33 \mathrm{E}-03$ & 0.035 & 1.388 & 0.473 \\
Apoptosis: FADD, TRADD & UP & 2.722 & $4.33 \mathrm{E}-03$ & 0.035 & 1.358 & 0.442 \\
Apoptosis: TRAF2, RIPK1, TRADD & UP & 2.722 & $4.33 \mathrm{E}-03$ & 0.035 & 1.358 & 0.442 \\
Toll-like receptor signaling pathway: TNF & UP & 2.722 & $4.33 \mathrm{E}-03$ & 0.035 & 1.434 & 0.520 \\
TNF signaling pathway: CASP7 & UP & 2.722 & $4.33 \mathrm{E}-03$ & 0.035 & 1.388 & 0.473 \\
TNF signaling pathway: CASP3 & UP & 2.722 & $4.33 \mathrm{E}-03$ & 0.035 & 1.371 & 0.455 \\
TNF signaling pathway: BAG4 & UP & 2.722 & $4.33 \mathrm{E}-03$ & 0.035 & 1.391 & 0.476
\end{tabular}

a $\mathrm{P}$-value is calculated using Wilcoxon test

${ }^{b}$ FDR refers to $p$-value adjusted for multiple comparisons using Benjamini and Hochberg method

${ }^{\mathrm{C}} \mathrm{FC}$ means Fold Change

well-known [30, 31], moreover, interferon is a key player in TNF signaling pathway [32], and both signaling pathways are interrelated. Beyong the pure interpretation of the results, another novel and very useful option of the implementation of the model is the Perturbation effect. It allows estimating the effect of interventions (inhibitions or overexpression) across the signaling circuits of the model in a given condition. Moreover, the effect of more than 8000 targeted drugs from DrugBank can be predicted by selecting them, individually or in combinations. Figure $1 \mathrm{~d}$ shows and example of the Perturbation effect option in which the impact of Siltuximab, a drug in study in patients with COVID-19 respiratory failure [33] which targets protein IL6, is simulated. Individual gene expression levels in each node are represented in shades of grayish green. Figure 1e, shows an example of the Variant interpreter option simulating the effect of a

Table 2 Functions from CoV-Hipathia differentially activated in lung cell lines infected with SARS-CoV-2

\begin{tabular}{|c|c|c|c|c|c|c|}
\hline UniProt function & UP/DOWN & statistic & p-value ${ }^{a}$ & FDR $^{\mathbf{b}}$ & $\mathrm{FC}^{\mathrm{c}}$ & $\log \mathrm{FC}$ \\
\hline Innate immunity & UP & 2.882 & $2.16 \mathrm{E}-03$ & 0.018 & 1.048 & 0.067 \\
\hline Immunity & UP & 2.882 & $2.16 \mathrm{E}-03$ & 0.018 & 1.019 & 0.028 \\
\hline Inflammatory response & UP & 2.882 & $2.16 \mathrm{E}-03$ & 0.018 & 1.028 & 0.041 \\
\hline Antiviral defense & UP & 2.882 & $2.16 \mathrm{E}-03$ & 0.018 & 1.192 & 0.253 \\
\hline Pyrogen & UP & 2.882 & $2.16 \mathrm{E}-03$ & 0.018 & 1.177 & 0.235 \\
\hline Prostaglandin biosynthesis & UP & 2.882 & $2.16 \mathrm{E}-03$ & 0.018 & 1.267 & 0.341 \\
\hline Prostaglandin metabolism & UP & 2.882 & $2.16 \mathrm{E}-03$ & 0.018 & 1.267 & 0.341 \\
\hline Fatty acid biosynthesis & UP & 2.882 & $2.16 \mathrm{E}-03$ & 0.018 & 1.266 & 0.341 \\
\hline Lipid biosynthesis & UP & 2.882 & $2.16 \mathrm{E}-03$ & 0.018 & 1.266 & 0.341 \\
\hline Acute phase & UP & 2.882 & $2.16 \mathrm{E}-03$ & 0.018 & 1.526 & 0.610 \\
\hline Osteogenesis & UP & 2.882 & $2.16 \mathrm{E}-03$ & 0.018 & 1.181 & 0.241 \\
\hline Autophagy & DOWN & -2.722 & 4.33E-03 & 0.028 & 0.976 & -0.035 \\
\hline Translation regulation & UP & 2.722 & 4.33E-03 & 0.028 & 1.015 & 0.022 \\
\hline Sphingolipid metabolism & UP & 2.722 & 4.33E-03 & 0.028 & 1.388 & 0.473 \\
\hline Necrosis & UP & 2.562 & 8.66E-03 & 0.046 & 1.009 & 0.013 \\
\hline Fibrinolysis & UP & 2.562 & 8.66E-03 & 0.046 & 1.103 & 0.141 \\
\hline Plasminogen activation & UP & 2.562 & 8.66E-03 & 0.046 & 1.072 & 0.101 \\
\hline
\end{tabular}

${ }^{a}$ P-value is calculated using Wilcoxon test

${ }^{b}$ FDR refers to $p$-value adjusted for multiple comparisons using Benjamini and Hochberg method

c FC means Fold Change 
loss of function mutation in NFKBIA gene product over lung tissue pathway activity. One of the affected circuits in TNF signaling pathway is shown. Mean values of gene expression levels in each node are represented in shades of grayish green. A detailed description of the usage of the tool can be found in the accompanying help and tutorial.

Despite the limitations due to the few samples available, the results of the example clearly show the usefulness of this tool for modelling the repertoire of cell responses triggered by SARS-CoV-2, and the enormous potential that it has for future COVID-19 research and discovery of therapeutic interventions. Moreover, in spite of its short life CoV-Hipathia has already been quoted among other useful web tools to fight the COVID-19 pandemic [34] .

Acknowledgements

Not applicable.

\section{Authors' contributions}

KR developed the mechanistic modeling software, MEM carried out the mechanistic modeling analysis, MRL developed the algorithm, CL implemented the predictors in the software, DG and MO developed the COVID-10 disease map, JD and MPC conceived the work and wrote the paper. All authors read and approved the final manuscript.

\section{Funding}

This work is supported by grants SAF2017-88908-R from the Spanish Ministry of Economy and Competitiveness, PT17/ 0009/0006, ACCI2018/29 from CIBER-ISCIII and COV20/00788 from the ISCIII, Co-funded with European Regional Development Funds (ERDF), the grant "Large-scale drug repurposing in rare diseases by genomic Big Data analysis with machine learning methods" from the Fundación BBVA (G999088Q), as well as H2020 Programme of the European Union grants Marie Curie Innovative Training Network "Machine Learning Frontiers in Precision Medicine" (MLFPM) (GA 813533).

\section{Availability of data and materials}

The dataset used during the current study is available in the GEO database, [https://www.ncbi.nlm.nih.gov/geo/query/ acc.cgi?acc=GSE147507], the COVID-19 Disease Map used here is available [https://doi.org/10.5281/zenodo.3935733], and new versions will be made publicly available here [https://doi.org/10.17881/covid19-disease-map].

This tool freely available at: http://hipathia.babelomics.org/covid19/

\section{Ethics approval and consent to participate}

Not applicable.

\section{Consent for publication}

Not applicable.

\section{Competing interests}

The authors declare that they have no competing interests.

\section{Author details}

${ }^{1}$ Bioinformatics Area, Fundación Progreso y Salud (FPS), Hospital Virgen del Rocío, Sevilla, Spain. ${ }^{2}$ Computational Systems Medicine, Institute of Biomedicine of Seville (IBIS), Hospital Virgen del Rocio, 41013 Sevilla, Spain. ${ }^{3}$ Bioinformatics and Biostatistics Unit, Centro de Investigación Príncipe Felipe (CIPF), 46012 Valencia, Spain. ${ }^{4}$ Bioinformatics in RareDiseases (BiER), Centro de Investigación Biomédica en Red de Enfermedades Raras (CIBERER), Sevilla, Spain. ${ }^{5}$ Luxembourg Centre for Systems Biomedicine, University of Luxembourg, L-4367 Belvaux, Luxembourg.

${ }^{6}$ Functional Genomics Node (INB-ELIXIR-es), Sevilla, Spain.

Received: 21 July 2020 Accepted: 5 January 2021

Published online: 21 January 2021

\section{References}

1. Wang C, Horby PW, Hayden FG, Gao GF. A novel coronavirus outbreak of global health concern. Lancet. 2020; 395(10223):470-3.

2. Ostaszewski M, Gebel S, Kuperstein I, Mazein A, Zinovyev A, Dogrusoz U, et al. Community-driven roadmap for integrated disease maps. Briefings Bioinformatics. 2019;20(2):659-70.

3. Gordon DE, Jang GM, Bouhaddou M, Xu J, Obernier K, White KM, et al. A SARS-CoV-2 protein interaction map reveals targets for drug repurposing. Nature. 2020;583(7816):459-68.

4. Ostaszewski M, Mazein A, Gillespie ME, Kuperstein I, Niarakis A, Hermjakob H, et al. COVID-19 Disease Map, building a computational repository of SARS-CoV-2 virus-host interaction mechanisms. Scientific Data. 2020;7(1):136.

5. Mazein A, Ostaszewski M, Kuperstein I, Watterson S, Le Novère N, Lefaudeux D, et al. Systems medicine disease maps: community-driven comprehensive representation of disease mechanisms. npj Systems Biol Applications. 2018;4(1):21. 
6. Yu MK, Kramer M, Dutkowski J, Srivas R, Licon K, Kreisberg JF, et al. Translation of genotype to phenotype by a hierarchy of cell subsystems. Cell Systems. 2016;2(2):77-88.

7. Hidalgo MR, Cubuk C, Amadoz A, Salavert F, Carbonell-Caballero J, Dopazo J. High throughput estimation of functional cell activities reveals disease mechanisms and predicts relevant clinical outcomes. Oncotarget. 2017;8(3):5160-78.

8. Çubuk C, Hidalgo MR, Amadoz A, Rian K, Salavert F, Pujana MA, et al. Differential metabolic activity and discovery of therapeutic targets using summarized metabolic pathway models. NPJ Systems Biology. 2019;5(1):7.

9. Cubuk C, Hidalgo MR, Amadoz A, Pujana MA, Mateo F, Herranz C, et al. Gene expression integration into pathway modules reveals a pan-cancer metabolic landscape. Cancer Research. 2018;78(21):6059-72.

10. Fey D, Halasz M, Dreidax D, Kennedy SP, Hastings JF, Rauch N, et al. Signaling pathway models as biomarkers: Patientspecific simulations of JNK activity predict the survival of neuroblastoma patients. Sci Signal. 2015;8(408):ra130

11. Hidalgo MR, Amadoz A, Cubuk C, Carbonell-Caballero J, Dopazo J. Models of cell signaling uncover molecular mechanisms of high-risk neuroblastoma and predict disease outcome. Biology Direct. 2018;13(1):16.

12. Chacón-Solano E, León C, Díaz F, García-García F, García M, Escámez M, et al. Fibroblasts activation and abnormal extracellular matrix remodelling as common hallmarks in three cancer-prone genodermatoses. J British Journal of Dermatology. 2019;181(3):512-22.

13. Peña-Chilet M, Esteban-Medina M, Falco MM, Rian K, Hidalgo MR, Loucera C, et al. Using mechanistic models for the clinical interpretation of complex genomic variation. Scientific Reports. 2019;9(1):1-12.

14. Amadoz A, Sebastian-Leon P, Vidal E, Salavert F, Dopazo J. Using activation status of signaling pathways as mechanismbased biomarkers to predict drug sensitivity. Scientific Reports. 2015;5:18494.

15. Falco MM, Peña-Chilet M, Loucera C, Hidalgo MR, Dopazo J. Mechanistic models of signaling pathways deconvolute the glioblastoma single-cell functional landscape. NAR Cancer. 2020;2(2):zcaa011.

16. Saez-Rodriguez J, Blüthgen N. Personalized signaling models for personalized treatments. Molecular Systems Biology. 2020;16(1):e9042.

17. Hastings JF, O'Donnell Y, Fey D, Croucher DR. Applications of personalised signalling network models in precision oncology. Pharmacology Therapeutics. 2020;212:107555.

18. Razzoli M, Frontini A, Gurney A, Mondini E, Cubuk C, Katz LS, et al. Stress-induced activation of brown adipose tissue prevents obesity in conditions of low adaptive thermogenesis. Molecular Metabolism. 2016;5(1):19-33.

19. Ferreira PG, Muñoz-Aguirre M, Reverter F, CPS G, Sousa A, Amadoz A, et al. The effects of death and post-mortem cold ischemia on human tissue transcriptomes. Nature Communications. 2018, 9(1):490.

20. Hernansaiz-Ballesteros RD, Salavert F, Sebastian-Leon P, Aleman A, Medina I, Dopazo J. Assessing the impact of mutations found in next generation sequencing data over human signaling pathways. Nucleic Acids Res. 2015;43(W1): W270-5.

21. Salavert F, Hidalgo MR, Amadoz A, Cubuk C, Medina I, Crespo D, et al. Actionable pathways: interactive discovery of therapeutic targets using signaling pathway models, Nucleic Acids Res. 2016;44(W1):W212-6.

22. Esteban-Medina M, Peña-Chilet M, Loucera C, Dopazo J. Exploring the druggable space around the Fanconi anemia pathway using machine learning and mechanistic models. BMC Bioinformatics. 2019;20(1):370.

23. Kanehisa M, Sato Y, Kawashima M, Furumichi M, Tanabe M. KEGG as a reference resource for gene and protein annotation. Nucleic Acids Research. 2015;44(D1):D457-D62.

24. UniProt_Consortium. UniProt: a worldwide hub of protein knowledge. Nucleic acids research. 2018;47(D1):D506-D15.

25. Amadoz A, Hidalgo MR, Çubuk C, Carbonell-Caballero J, Dopazo J. A comparison of mechanistic signaling pathway activity analysis methods. Briefings Bioinformatics. 2019;20(5):1655-68.

26. Mitsos A, Melas IN, Siminelakis P, Chairakaki AD, Saez-Rodriguez J, Alexopoulos LG. Identifying drug effects via pathway alterations using an integer linear programming optimization formulation on phosphoproteomic data. PLoS Comput Biol. 2009;5(12):e1000591.

27. Blanco-Melo D, Nilsson-Payant BE, Liu WC, Uhl S, Hoagland D, Møller R, et al. Imbalanced Host Response to SARS-CoV-2 Drives Development of COVID-19. Cell. 2020;181(5):1036-45 e9.

28. Gao J, Tian Z, Yang X. Breakthrough: Chloroquine phosphate has shown apparent efficacy in treatment of COVID-19 associated pneumonia in clinical studies. Bioscience trends. 2020;14:72-73.

29. Zhou Y, Hou Y, Shen J, Huang Y, Martin W, Cheng F. Network-based drug repurposing for novel coronavirus 2019nCoV/SARS-CoV-2. Cell Discovery. 2020;6(1):1-18.

30. Tsuboi N, Yoshikai Y, Matsuo S, Kikuchi T, Iwami K, Nagai Y, et al. Roles of toll-like receptors in C-C chemokine production by renal tubular epithelial cells. J Immunol. 2002;169(4):2026-33.

31. Perkins DJ, Vogel SN. Space and time: New considerations about the relationship between Toll-like receptors (TLRs) and type I interferons (IFNs). Cytokine. 2015;74(2):171-4.

32. Yarilina A, Ivashkiv LB. Type I interferon: a new player in TNF signaling. Curr Dir Autoimmun. 2010;11:94-104

33. Gritti G, Raimondi F, Ripamonti D, Riva I, Landi F, Alborghetti L, et al. IL-6 signalling pathway inactivation with siltuximab in patients with COVID-19 respiratory failure: an observational cohort study. medRxiv. 2020:2020.04.01.20048561.

34. Mercatelli D, Holding AN, Giorgi FM. Web tools to fight pandemics: the COVID-19 experience. Brief Bioinform. 2020: bbaa261. https://doi.org/10.1093/bib/bbaa261. Epub ahead of print.

\section{Publisher's Note}

Springer Nature remains neutral with regard to jurisdictional claims in published maps and institutional affiliations. 